\begin{tabular}{ll}
\hline & $\begin{array}{l}\text { Kastamonu Eğitim Dergisi } \\
\text { Kastamonu Education Journal }\end{array}$ \\
$\begin{array}{l}\text { Temmuz } 2019 \text { Cilt:27 Sayı:4 } \\
\text { kefdergi.kastamonu.edu.tr }\end{array}$ & Başvuru Tarihi/Received: 13.06 .2018 \\
Kabul Tarihi/Accepted: 06.11 .2018 \\
Dol: $10.24106 /$ kefdergi.3152
\end{tabular}

\title{
Ortaokul Düzeyinde Geometriye Yönelik Bir Tutum Ölçeğinin Geliştirilmesi ${ }^{1}$
}

\section{Development of a Scale of Attitudes toward Geometry in Middle School Level}

\author{
Selda ÖZDişçi², Yasemin KATRANCl ${ }^{3}$
}

Öz

Bu çalışmanın amacı ortaokul düzeyinde öğrenim görmekte olan öğrencilerin geometriye yönelik tutumlarını belirlemek için bir ölçeğin geliştirilmesidir. Bu amaçla çalışma tarama modeline göre tasarlanmıştır. Çalışma grubunun belirlenmesinde uygun/kazara örnekleme yöntemi ele alınmış ve çalışma İzmir ilindeki bir devlet ortaokulunda gerçekleştirilmiştir. Çalışmaya bu ortaokulda öğrenim görmekte olan 640 ortaokul öğrencisi katılmıştı. Ölçeğin faktör yapısının belirlenmesi için açımlayıcı faktör analizi ve ortaya konan yapının sınanması amacıyla doğrulayıcı faktör analizi yapılmıştır. Madde analizleri gerçekleştirilerek, iç tutarlılığın belirlenmesi için de Cronbach alfa güvenirlik analizleri yapılmıştır. Açımlayıcı faktör analizi sonucunda ölçeğin üç faktörden meydana geldiği belirlenmiştir. Bu faktörler; Olumlu tutumlar, Olumsuz tutumlar ve Teknolojidir. Doğrulayıcı faktör analizi sonuçlarına göre ölçeğin mükemmel derecede uyum sergilediği belirlenmiştir. Madde analizleri sonucunda ise ölçekte yer alan maddelerin yeterince ayırt edici, yüksek geçerliğe sahip ve aynı yapıyı ölçen maddeler oldukları ortaya konmuştur. Güvenirlik analizleri ile ölçek ve ölçek alt faktörlerinin yeterince güvenilir oldukları tespit edilmiştir. Sonuçta geliştirilen ölçeğin ortaokul öğrencilerinin geometriye yönelik tutumlarının belirlenmesinde kullanılabilecek geçerli ve güvenilir bir araç olduğu ortaya çıkmıştir.

\section{Anahtar Kelimeler: geometri, ortaokul, tutum, ölçek geliştirme}

\section{Abstract}

The aim of this study was to develop a scale to determine middle school students' attitudes towards geometry. The study was designed as a screening model. The study group was designed according to convenience sampling. Therefore, the study was conducted in a middle school which is located in izmir. 640 middle school students who were studying at this school participated in this study. In order to determine a factor structure of the scale, exploratory factor analysis was used and to verify this structure confirmatory factor analysis was used. Item analyses were performed. Cronbach alpha was also calculated to determine internal consistency reliability. It was found that the scale has three sub-factors according to exploratory factor analysis. These sub-factors are as follows: Positive attitudes, Negative attitudes, and Technology. It was seen that the scale showed perfect agreement according to confirmatory factor analysis. As a result of the item analyses, it was revealed that the items in the scale were sufficiently distinguishable, had high validity, and measured the same structure with the scale. The reliability analyses showed that the scale and the scale's sub-factors were reliable. As a result, it was found that the scale which could be used in order to determine middle school students' attitudes towards geometry was a valid and reliable instrument.

Keywords: geometry, middle school, attitude, scale development

\footnotetext{
1. Bu çalışma, ilk yazarın "Geometriye Yönelik Tutum Ölçeği Geliştirilmesi ve Değerlendirilmesi” başlıklı yüksek lisans tezinin bir bölümüdür.

2. Zihni Üstün Ortaokulu, İmir, Türkiye; https://orcid.org/0000-0001-9215-0310

3. Kocaeli Üniversitesi, Eğitim Fakültesi, Türkiye; https://orcid.org/0000-0002-0916-2407

Atıf / Citation: Özdişçi, S., \& Katrancı (2019). Ortaokul düzeyinde geometriye yönelik bir tutum ölçeğinin geliştirilmesi.Kastamonu Education Journal, 27(4), 15631573. doi:10.24106/kefdergi.3152
} 


\section{Extended Abstract}

In this study, it was aimed to develop a scale to determine middle school students' attitudes towards geometry. In order to reach this aim, following questions were examined:

1. What are the results of exploratory factor analysis (EFA) of the scale of attitudes towards geometry?

2. What are item-total correlations, item-remainder correlations, and item discriminations of the scale?

3. What are the results of confirmatory factor analysis (CFA) of the scale?

4. What are the results of reliability analyses of the scale?

The study was designed as a screening model and conducted in a middle school which is located in izmir. 640 middle school students who were studying in this school participated in this study. Exploratory factor analysis was used in order to determine a factor structure of the scale. Item analyses were also calculated. In addition to this, confirmatory factor analysis was used in order to verify this factor structure of the scale. After this process, reliability analyses were performed to determine internal consistency.

First, an item pool was designed to develop the scale. Items were organized according to an expert opinion form. And then experts' opinions were solicited. After this process, the scale was adapted to an application. After collecting data, exploratory factor analysis was performed. As a result of this analysis, it was seen that the scale has three sub-factors. These sub-factors are positive attitudes, negative attitudes, and technology. It was calculated that the scale's explained total variance was $57.453 \%$. It was considered that the explained total variance ranges between $40 \%$ and $60 \%$ in multi-factor scale development studies (Çokluk, Şekercioğlu, \& Büyüköztürk, 2010). In this context, the obtained total variance percentage was acceptable.

Then, item analyses were done. It was found that the items in the scale were sufficiently distinguishable, had high validity, and measured the same structure with the scale. Correlations between the scale and the scale's sub-factors were examined. Büyüköztürk (2012) expresses that if the correlation coefficient is between .30 and .70, it is called moderate level correlation. If the correlation coefficient is between .70 and 1.00, it is called high level correlation. It was seen that a correlation coefficient between the scale and positive attitudes was found as .788, indicating a high level correlation. It was found that the correlation coefficients for negative attitudes and technology were found as .619 and .677, respectively. In this context, it was determined that these factors show moderate level correlations with the scale.

After item analyses, confirmatory factor analysis was conducted. As a result of this analysis, the index of $\mathrm{X}^{2} / \mathrm{df}$ was found as 2.21. This index showed that the expressed scale was perfect fit (see the Table 6). It was considered that all the fit indexes which were presented in Table 6 were found to be acceptable.

Lastly, reliability analyses of the scale were calculated. The Cronbach alpha coefficient of the whole scale was found as .886. It was found that the reliability coefficients of the positive, negative, and technology sub-factors were calculated as .924, .728, and .909, respectively. Since reliability coefficient is calculated as .70 and above, it is generally considered sufficient (Büyüköztürk, 2012). Therefore, all the calculated reliability coefficients were considered sufficient.

In conclusion, a valid and reliable scale was developed in order to determine attitudes towards geometry of students who are studying in middle schools. It should be investigated whether the scale could be used at primary and high school levels. For this reason, it is suggested that new studies should be organized in which students studying at this levels are identified as a study group. 


\section{Giriş}

İnsanın etrafinı saran varlıkların veya eşyaların çoğu geometrik cisim ve şekillerdir. Bireyler işlerini yürütürken geometrik cisim ve şekilleri kullanmaktadırlar. Bu cisim ve şekillerden en etkili şekilde yararlanmak ise bunları tanımaya, cismin şekli ve görevi arasındaki ilişkiyi anlamaya dayanmaktadır (Bindak, 2004). Bu da geometriyi anlamayla mümkündür. İnsan yaşamında önemli bir yere sahip olan geometri, bilimden sanata kadar en erken çağlardan beri önemli görülmüştür (Van de Walle, 2001). Geometri, nokta, çizgi, açı, yüzey ve cisimlerin birbirleri ile olan ilişkilerini, ölçümlerini ve özelliklerini inceleyen bilim dalı (TDK [Türk Dil Kurum], 2018) olarak ifade edilmektedir. Geometri, öğrencilerin dünyayı anlama ve temsil etmeleri, problemleri anlamaları, analiz etmeleri ve çözmeleri için soyut sembollerin resimsel olarak gösterilmesine yardımcı olan matematiğin bir alt dalı olarak görülmektedir (Struchens, Harris, \& Martin, 2001).

Geometri matematikte öğrencilerin karşılaştırma, genelleme, özetleme ve problem çözme becerilerinin geliştirilmesine yardımcı olmaktadır (Napitupulu, 2001). Bu süreçte öğrenciler geometrik şekilleri anlamakta ve şekiller arasındaki ilişkileri analiz etmeyi öğrenmektedirler (Bal, 2014). Bu bağlamda geometri öğrenme alanının amacı, düzlemde ve üç boyutlu uzayda geometrik nesnelerin özelliklerini tanıma, nesne ve özellikleri arasındaki ilişkileri bulma, geometrik yerin tanımını yapma, dönüşümleri ifade etme ve açıklama ile geometrik önermeleri ispatlama olarak ifade edilmiştir (Baki, 2008). Ancak bu amaca ulaşmada öğrencilerin pek çok zorlukla karşılaşt̆ğı belirtilmektedir (Yenilmez \& Uygan, 2010). Bu durum Uluslararası Matematik ve Fen Eğilimleri Araştırması (TIMSS, 2011) raporu incelendiğinde de karşımıza çıkmaktadır. Sekizinci sınıf öğrencilerinin sayılar, cebir ve geometri alanlarındaki soruları veri ve olasılık alanındaki sorulara göre daha zor buldukları görülmektedir. Sekizinci sınıfların başarı düzeyinin ise orta yeterlilik düzeyinde olduğu görülmektedir. Bu durum dördüncü sınıf öğrencilerinde de benzerdir. Dördüncü sınıflar sayılar ve geometri alanındaki soruları veri gösterimi sorularına göre daha zor bulmuşlardır. Başarı düzeyleri ise alt yeterlilik düzeyindedir (Büyüköztürk, Çakan, Tan, \& Atar, 2014a, 2014b). Öğrencilerin bu zorluklarla karşılaşma sebeplerinden bir tanesinin olumsuz duyuşsal özellikler olduğu belirtilmektedir (Yenilmez \& Uygan, 2010). Ülkemiz matematik dersi öğretim programında geometriye yönelik amaçlara ulaşıımasının yanı sıra, başta tutum olmak üzere duyuşsal özelliklerin de geliştirilmesi, başarıyı beraberinde getirmesi sebebiyle önemli görülmektedir (MEB, 2017). Taşdemir (2008) ilköğretimden üniversiteye kadar öğrencilerin en çok korktukları ve çekindikleri derslerin başında matematiğin geldiğini belirtmiş, bir derse yönelik olumlu tutumun ise o dersteki başarıyı olumlu yönde etkileyeceğini ifade etmiştir. Bu kapsamda geometriye yönelik olumlu tutumun geliştirilmesi de önem taşımaktadır.

Tutum bazı uyaranların oluşturduğu tepki sınıfları (hoşlanma-hoşlanmama, inanışlar, fikirler, görüşler vb. gibi) ile cevap verme eğilimi olarak tanımlanmaktadır (Tavşancıl, 2002). Geometriye yönelik tutum ise kişinin geometri, geometri ile ilgili etkinlikler, öğretmen ve geometrinin kendi üzerindeki etkisine yönelik duygu, düşünce ve davranışlarını içeren bir eğilim olarak ifade edilmektedir (Bindak, 2004). Geometriden hoşlanma-hoşlanmama, geometride iyi-kötü olduğuna yönelik inançların ve geometrinin yararına yönelik inançların belirlenmesi olarak da belirtilmektedir (Kaba, Boğazııan, \& Daymaz, 2016). Bu tanımlardan yola çıkılarak geometriye yönelik tutum, uyaranlara (geometri, geometri etkinlikleri, geometri öğretmeni, vs.) karşı bireyin hoşlanma ya da hoşlanmama durumu, uyaranların iyi veya kötü olduklarına yönelik inancı ve bu uyaranlara karşı gösterdiği davranış olarak tanımlanabilir. Genel olarak tutumlar merak ve değerlendirme özelliklerini kapsamakta ve bireyde bir şeye karşı ilgi uyanmasını sağlamaktadırlar. Öğrenmenin olup olmamasının yanında bireyin öğrenme tarzını da etkilemektedirler (Atasoy, 2004). Geometriye yönelik tutumların da geometri öğrenmeyi etkilediği aşikardır. Tutumlar davranışlara yön vermekte olup ölçülmesi önemli görülmektedir (Bindak, 2004). Öğrenmeyi etkilemesi sebebiyle tutumları etkileyen unsurların belirlenmesinin, değerlendirilmesinin ve gerekli önlemlerin alınmasının eğitimde istenilen amaçlara ulaşılması bakımından önemli olduğu düşünülmektedir (Avcl, Coşkuntuncel, \& İnandı, 2011). Geometrinin de, gerek duyuşsal gerekse bilişsel düzeyde incelenmesinin, öğrenimi ve öğretimi açısından önemli olduğu belirtilmiştir (Ünlü \& Ertekin, 2018). Bu çerçevede geometriye yönelik tutumların geometride istenilen amaçlara ulaşılması bakımından belirlenmesi önemlidir. Bu ölçümlerin yapılabilmesi için ise ilgili konuya yönelik ölçme araçlarının geliştirilmesinin gerektiği düşünülmektedir. Ülkemiz ilk ve ortaokul öğrencilerinin uluslararası sınavlardaki geometri başarıları da dikkate alındığında, bu ölçümlerin güncel araçlarla yapılmasının önemi ortaya çıkmaktadır. Gerekli ölçümlerin güncel bir şekilde yapılabilmesi için de geometriye yönelik bir tutum ölçeğinin geliştirilmesinin önemli ve gerekli olduğu ön görülmektedir.

İlgili literatür incelendiğinde, Bulut, Ekici, İşeri ve Helvacı (2002) sekizinci ve onuncu sınıf öğrencileri ile geometriye yönelik bir tutum ölçeği geliştirme çalışması gerçekleştirmişlerdir. Bindak (2004) ise lise öğrencilerinin geometriye yönelik tutumlarını ölçen geçerli ve güvenilir bir araç geliştirmiştir. Bayram (2004) dokuzuncu ve onuncu sınıf öğrencileri ile gerçekleştirdiği çalışmasında, Bulut ve diğerlerinin (2002) çalışmasını referans alarak bir geometri tutum ölçeği geliştirmiştir. Mogari (2004) de benzer şekilde Aiken'in (1979) matematiğe yönelik tutum ölçeğini referans alarak geometri- 
ye yönelik bir ölçek geliştirmiştir. Güven (2006) altıncı sınıf öğrencileri ile pilot uygulamasını gerçekleştirdiği çalışmasında geometrik çizimlere yönelik bir tutum anketi ortaya koymuştur. Utley (2007) tarafindan ise üniversite öğrencilerinin geometriye yönelik tutumlarını ölçmek amacıyla bir ölçek geliştirilmiştir. Duatepe-Paksu ve Ubuz (2007) sekizinci sınıf öğrencileri ile çalışarak bir geometri tutum ölçeği geliştirmişlerdir. Tutak (2008) dördüncü ve beşinci sınıf öğrencileri ile çalışarak geometriye yönelik bir tutum ölçeği ortaya koymuştur. Abdullah ve Zakaria (2011) 161 öğrenci ile Malezya'da gerçekleştirdikleri çalışmada geometriye yönelik bir tutum anketi oluşturmuşlardır. Cansız-Aktaş ve Aktaş (2013) tarafindan da lise öğrencilerinin geometriye yönelik tutumlarını ölçmek amacıyla bir ölçek geliștirilmiştir. Sunzuma, Masocha ve Zezekwa (2013) ise çalışmalarında Fennema-Shermann'ın (1976) matematik tutum ölçeğini referans alarak geometriye yönelik bir tutum ölçeği uyarlaması yaparak çalışmalarında bu ölçeği kullanmışlardır. Gürefe ve Kan (2013) ise öğretmen adayları için geometrik cisimler konusuna yönelik bir tutum ölçeği geliştirilmiştir.

Çalışmalar incelendiğinde belli bir sınıf düzeyi ile çalışıldığı, belli ölçekler referans alınarak geometriye yönelik ölçek geliştirildiği, hem ilkokul ortaokul seviyesinde hem de ortaokul lise seviyelerinden öğrencilerin çalışma grubu olarak belirlenmesiyle çalışmaların yapıldığı görülmüştür. Ancak ortaokulun tüm sınıf düzeylerinde öğrenim görmekte olan öğrencilerin geometriye yönelik tutumlarını ölçmeye yarayan bir ölçeğin geliştirilmediği tespit edilmiştir. Bu bağlamda bu çalışmada ortaokul düzeyinde öğrenim görmekte olan öğrencilerin geometriye yönelik tutumlarını ölçmek amacıyla bir ölçeğin geliştirilmesi amaçlanmıştır. Çalışma ortaokulun her düzeyindeki öğrenciler ile gerçekleştirilmesi bakımından farklı ve önemli görülmektedir. İlgili literatüre bu yönüyle katkı sağlayacağı düşünülmekte, ölçeğin gelecek çalışmalarda geometriye yönelik tutumların ortaokul düzeyinde ölçülmesinde kullanılabileceği düşünülmektedir. Ayrıca geometri kazanımları ilkokulun ilk yıllarından itibaren yer almaktadır. Bu açıdan bakıldığında ilkokul seviyesinde geliştirilebilecek olan bir ölçeğe de ışık tutacağı ön görülmektedir. Belirtilen amaca ulaşmak için ise aşağıdaki soruların cevapları araştrilmıştr.

1. Geometriye yönelik tutum ölçeğinin (GYTÖ) açımlayıcı faktör analizi (AFA) bulguları nelerdir?

2. Geliştirilen ölçeğin madde toplam-madde kalan ve madde ayırt edicilikleri nasıldır?

3. Ölçeğin doğrulayıcı faktör analizi (DFA) bulguları nelerdir?

4. Ölçeğin güvenirlik analizi bulguları nelerdir?

\section{Yöntem}

\section{Araştırma Modeli ve Çalışma Grubu}

Bu çalışma, bir grubun belirli özelliklerini belirlemek amacıyla verilerin toplanmasını içeren tarama araştırmasına (Büyüköztürk, Kılıç-Çakmak, Akgün, Karadeniz, \& Demirel, 2012) göre tasarlanmıştır. Çalışma grubunun belirlenmesinde ise uygun/kazara örnekleme yöntemi tercih edilmiştir. Bu yöntemde araştırmacı ihtiyaç duyduğu sayıdaki gruba ulaşana kadar en uygun ve en ulaşılabilir cevaplayıcılardan başlamak üzere örneklemini meydana getirir (Ravid, 1994). Bu doğrultuda çalışma İzmir ilinde bulunan bir devlet ortaokulunda yürütülmüştür. Çalışmaya bu ortaokulda öğrenim görmekte olan 640 öğrenci katılmıştır. Öğrencilerin cinsiyet ve sınıf seviyelerine göre dağııımı Tablo 1'de sunulmuştur.

Tablo 1: Çalışma Grubunun Cinsiyet ve Sınıf Seviyelerine Göre Dağııımı

\begin{tabular}{lccccc}
\hline & 5.Sınıf & 6.Sınıf & 7. Sınıf & 8. Sınıf & Toplam \\
\hline Kız (K) & 73 & 126 & 65 & 75 & $339(\% 52.97)$ \\
Erkek (E) & 60 & 96 & 72 & 73 & $301(\% 47.03)$ \\
Toplam & $133(\% 20.78)$ & $222(\% 34.69)$ & $137(\% 21.41)$ & $148(\% 23.13)$ & 640 \\
\hline
\end{tabular}

Çalışmaya katılan 640 öğrenciden elde edilen veriler rastgele ikiye bölünmüştür. Buradaki amaç açımlayıcı ve doğrulayıcı faktör analizlerini farklı gruplardan elde edilen verilerle yapmaktır. Bu bağlamda birinci gruptan elde edilen verilerle AFA, madde analizleri ve güvenirlik analizleri gerçekleştirilirken, ikinci gruptan elde edilen verilerle DFA gerçekleştirilmiştir. Buna göre, çalışma grubunun birinci ve ikinci gruplara dağııımı Tablo 2'de sunulmuştur.

Tablo 2: Çalışma Grubundaki Öğrencilerin Gruplara Dağılımı

\begin{tabular}{lllllll}
\hline Gruplar & Cinsiyet & 5.Sınıf & 6. Sınıf & 7. Sınıf & 8. Sınıf & Toplam \\
\hline \multirow{3}{*}{ Birinci Grup (AFA) } & Kız (K) & 35 & 66 & 33 & 37 & 171 \\
& Erkek (E) & 32 & 45 & 36 & 38 & 151 \\
& Toplam & 67 & 111 & 69 & 75 & 322 \\
\hline
\end{tabular}




\begin{tabular}{lllllll}
\hline Gruplar & Cinsiyet & 5.Sınıf & 6.Sınıf & 7.Sınıf & 8.Sınıf & Toplam \\
\hline \multirow{3}{*}{ İkinci Grup (DFA) } & Kız (K) & 38 & 60 & 32 & 38 & 168 \\
& Erkek (E) & 28 & 51 & 36 & 35 & 150 \\
& Toplam & 66 & 111 & 68 & 73 & 318 \\
\hline
\end{tabular}

Tablo 2 incelendiğinde 322 öğrenciden elde edilen veriler ile AFA, madde analizleri ve güvenirlik analizlerinin yapıldığı, 318 öğrenciden elde edilen veriler ile de doğrulayıcı faktör analizinin gerçekleştirildiği görülmektedir.

\section{Ölçeğin Geliştirilme Süreci: Geçerlik ve Güvenirlik}

Geometriye Yönelik Tutum Ölçeği (GYTÖ): Ilk olarak (yurt içi ve yurt dışı) ilgili literatür (Abdullah \& Zakaria, 2011; Bayram, 2004; Bindak, 2004; Bulut, Ekici, İşeri, \& Helvacı, 2002; Cansız-Aktaş \& Aktaş, 2013; Duatepe-Paksu \& Ubuz, 2007; Gürefe \& Kan, 2013, Güven, 2006; Mogari, 2004; Sunzuma, Masocha, \& Zezekwa, 2013; Tutak, 2008; Utley, 2007) incelenmiştir. Daha sonra Kocaeli ilinde bulunan bir devlet ortaokulunda öğrenim görmekte olan 35 altıncı ve sekizinci sınıf öğrencisinden geometriye yönelik duygu ve düşüncelerini içeren kompozisyon yazmaları istenmiştir. Bu uygulamanın ardından, üç matematik öğretmeninin görüşlerine de başvurulmuştur. Literatür taraması, öğrenci kompozisyonları ve öğretmen görüşleri dikkate alınarak 73 madde içeren bir madde havuzu oluşturulmuştur. Maddelerin yarısının olumlu yarısının olumsuz olmasına dikkat edilmiştir. Daha sonra uzman görüş formuna göre maddeler düzenlemiştir. Görüş formları dört matematik eğitimcisi ve bir program geliştirme uzmanına gönderilmiştir. Uzman görüşlerinin alınmasından sonra formlar bir araya getirilerek benzer ifadeler veya tutumu ölçmediği düşünülen maddeler ölçekten çıkarılmıştır. Fikir birliğinin sağlanamadığı maddeler de ölçekten çıkarılmış ve 30 maddeden oluşan taslak ölçek meydana getirilmiştir. Ardından ölçek beşli likert tipine dönüştürülmüştür. Beşli likert tipi için cevaplama anahtarı ise "hiç katılmıyorum, katılmıyorum, kısmen kathlıyorum, kathlıyorum, tamamen kathlıyorum" şeklinde belirlenmiştir. Ölçeğe demografik bilgiler de (cinsiyet ve sınıf düzeyi) eklenerek çalışma grubuna uygulanmıştır.

\section{Veri Analizi}

Sosyal bilimlerde ölçek geliştirme çalışmalarında, yapı geçerliğini ortaya koymak amacıyla kullanılan faktör analizi, ölçme aracının faktör yapısını ortaya çıkarmak adına yapıımaktadır (Çokluk, Şekercioğlu, \& Büyüköztürk, 2010). Analize geçilmeden önce ise bazı noktaların sorgulanması gerekmektedir. Bu noktalardan ilki örneklemin büyüklügüdür. Comrey ve Lee (1992) örneklem büyüklüğü için 50'nin çok zayıf, 300'ün iyi ve 1000'in mükemmel olduğunu belirtmektedirler. Yüksek yük değerlerine sahip madde elde etmek için ise 150 kişilik bir örneklemin yeterli olduğu ifade edilmektedir (Tabachnick \& Fidell, 2001). Kline (1994) ise örneklem büyüklüğünü belirlemek için madde sayısının dikkate alınması gerektiğini ve madde sayısının 10 kat bir örneklemin uygun olduğunu ortaya koymuştur. Bu çalışmadaki madde sayısı 30'dur. Açımlayıc faktör analizi için belirlenen örneklem büyüklüğü ise 322'dir. Bu bağlamda örneklem büyüklüğü madde sayısının 10 katı olması ve iyi olarak değerlendirilmesi sebebiyle yeterli görülmüştür.

Örneklem büyüklüğünün analiz açısından uygunluğunu test etmedeki diğer bir nokta, Kaiser-Meyer-Olkin (KMO) testi sonuçlarıdır (Kalaycı, 2005). KMO sonucunun .50'den düşük çıkması durumunda analize devam edilmeyeceği ifade edilmektedir. Bu değer .90 ve üzerinde ise örneklem analiz için mükemmel uygunluktadır denilmektedir (Şencan, 2005). Bu çalışma için hesaplanan KMO sonucu ise .936 bulunarak analizlere devam edilebileceği ortaya konmuştur. Bir diğer husus ise verilerin normal dağılımdan gelip gelmediğinin sorgulanmasıdır. Bunun için de Bartlett Küresellik Testi kullanılmaktadır. Bu testin anlamlılık değerinin .05'ten küçük çıkması faktör çıkarılabileceği anlamına gelmektedir ve veri setinin analiz için uygun olduğu anlamını taşımaktadır (Şencan, 2005). Bu çalışmada elde edilen küresellik testi sonucu ise $\left(X^{2}=5544.47 ; p<.05\right)$ veri setinin analize uygun olduğunu göstermiştir. Örneklem büyüklüğü ve normalliğin değerlendirilmesinden sonra AFA gerçekleştirilmiştir.

AFA ile ortaya konan yapının sınanması amacıyla DFA yapılmıştır. Madde analizleri gerçekleştirilmiştir. Geliştirilen ölçeğin iç tutarlığının belirlenmesi için de Cronbach alfa güvenirlikleri hesaplanmıştır.

\section{Bulgular}

Birinci Araştırma Problemi: Geometriye yönelik tutum ölçeğinin (GYTÖ) açımlayıcı faktör analizi (AFA) bulguları nelerdir?

Temel bileşenler analizi yapılarak dik döndürme yöntemlerinden varimax kullanılmıştır. Verilerin kaç faktörde toplandığının belirlenmesinde ise yamaç-birikinti grafiği ile öz değer istatistiği göz önüne alınmıştır (Büyüköztürk, 2012). Öz değeri birden yüksek faktörler göz önünde bulundurulmuş ve üç faktörün öz değerlerinin birden büyük olduğu görülmüştür. Yamaç-birikinti grafiği incelendiğinde ise üçüncü faktörden sonra grafiğin yatay bir seyir izlediği belirlenmiştir. Bu bağlamda ölçeğin faktör sayısının üç olmasına karar verilmiştir. Analiz sonucu elde edilen yamaç birikinti grafiği aşağıda Şekil 1'de ve öz-değerler ile ilgili bilgiler Tablo 3'te sunulmuştur. 


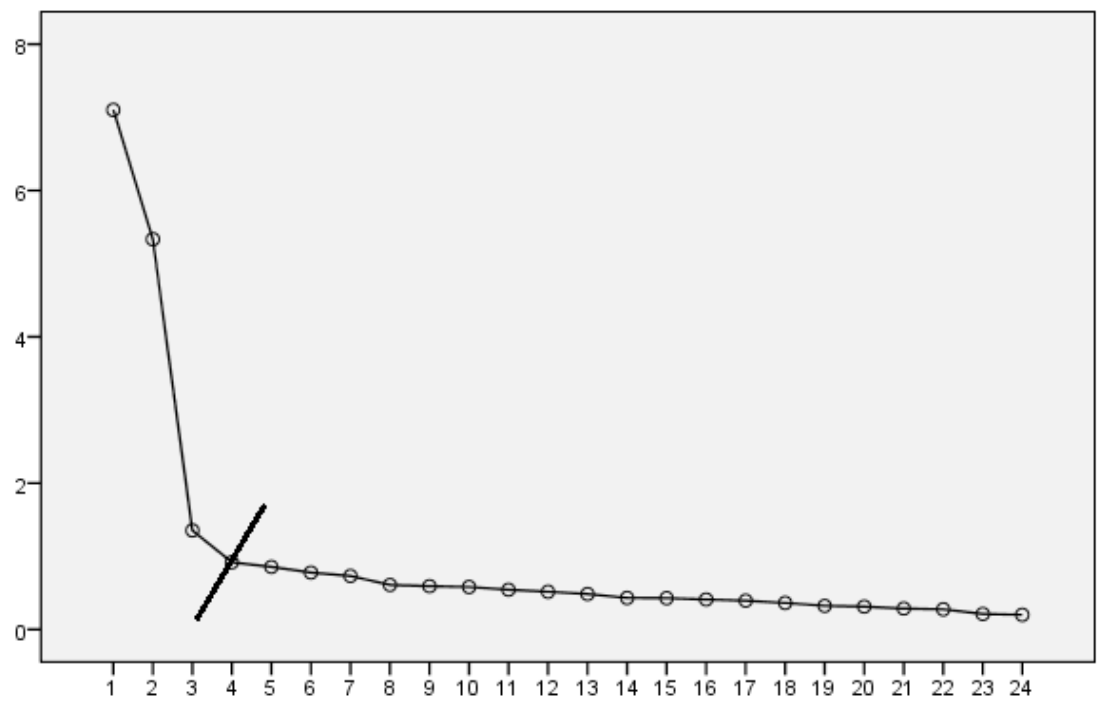

Şekil 1. GYTö’nün Yamaç Birikinti Grafiği

Faktör sayısının belirlenmesinin ardından dikkat edilmesi gereken nokta, faktörlerin yük değerleridir. Faktör yük değerinin düşük olması, ilgili faktör ile ilişkisinin zayıflı̆ını göstermektedir. Asgari büyüklüğün .30 olması önerilmektedir (Şencan, 2005). Yük değerinin .32 olması gerektiği ayrıca belirtilmektedir (Tabachnick \& Fidell, 2001). Ancak bu değerin kabulü halinde varyansın sadece \%10'unun açıklanabileceği ifade edilmektedir. Yük değerlerinin .45 olması halinde ise varyansın \%20'sinin açıklanabileceği belirtilmektedir (Comrey \& Lee, 1992). Bu bağlamda bu çalışmada faktör yük değerlerinin .45 olmasına karar verilmiştir. Faktör sayısı üç ve faktör yük değerleri .45 olmak üzere analiz işlemleri yinelenmiştir. Analiz sonuçları maddelerin binişiklikleri de göz önünde bulundurularak değerlendirilmiş ve altı maddenin ölçekten çıkarılmasına karar verilmiştir. Sonuçta ölçekte 24 madde kalmıştır. 24 maddenin faktörlere dağılımları incelenmiş ve faktörlerin isimlendirilmesi gerçekleştirilmiştir. Buna göre faktörler; "Olumlu Tutumlar", "Olumsuz Tutumlar" ve "Teknoloji" olarak adlandırılmışlardır. Olumlu tutumlar ile ilgili maddeler; 1, 3, 6, 8, 11, 14, 16, 18 ve 20'dir. Olumsuz tutumlar ile ilgili maddeler; 5, 9, 12, 22 ve 24'tür. Teknoloji faktörü ile ilgili maddeler ise; 2, 4, 7, 10, 13, 15, 17, 19, 21 ve 23'tür. 24 maddeden meydana gelen ölçeğin son hali EK 1'de sunulmuştur. Aşağıda Tablo 3'te ise AFA sonuçları görülebilmektedir.

Tablo 3. GYTÖ’nün AFA Bulguları

\begin{tabular}{cccc}
\hline Madde No & Olumlu Tutumlar & Olumsuz Tutumlar & Teknoloji \\
\hline 1 & .693 & & \\
3 & .811 & & \\
6 & .734 & & \\
8 & .826 & & \\
11 & .772 & & \\
14 & .749 & & \\
16 & .781 & & \\
18 & .641 & & \\
20 & .778 & .530 & \\
5 & & .621 & \\
9 & & .656 & .702 \\
12 & & .605 & .789 \\
22 & & .741 & .806 \\
24 & & & .815 \\
2 & & & .786 \\
4 & & & .747 \\
7 & & & .769 \\
10 & & & .748 \\
13 & & & .566 \\
15 & & & 5.334 \\
17 & & & \\
19 & & & \\
21 & & & \\
23 & & & \\
Birikimli Varyans \% & & & \\
\hline Özdeğer & & & \\
Varyans \% & & & \\
\hline
\end{tabular}

| Kastamonu Eğitim Dergisi, 27(4), 2019| 
Tablo 3 incelendiğinde faktör yük değerlerinin .530 ile .826 arasında olduğu görülmektedir. Açıklanan toplam varyans ise $\% 57.453$ olarak belirlenmiştir.

İkinci Araştırma Problemi: Geliştirilen ölçeğin madde toplam-madde kalan ve madde ayırt edicilikleri nasıldır?

Araştırmanın ikinci probleminin cevabına ulaşmak için madde puanı ile toplam puan arasındaki korelasyon (MPTK), madde kalan korelasyonu (MKK) ve t-testi gerçekleştirilmiştir. Alt \%27'lik ve üst \%27'lik gruplar belirlenerek her iki grubun karşılaştırması yapılmıştır. Elde edilen bulgular aşağıda Tablo 4'te sunulmuştur.

Tablo 4. GYTÖ’nün Madde Analizi Bulguları

\begin{tabular}{|c|c|c|c|c|c|c|c|c|c|c|c|}
\hline \multicolumn{4}{|c|}{ Olumlu Tutumlar } & \multicolumn{4}{|c|}{ Olumsuz Tutumlar } & \multicolumn{4}{|c|}{ Teknoloji } \\
\hline $\mathrm{MN}$ & MKK & MPTK & $\mathrm{t}^{*}$ & $\mathrm{MN}$ & MKK & MPTK & $\mathrm{t}$ & $\mathrm{MN}$ & MKK & MPTK & $t^{*}$ \\
\hline 1 & .562 & .512 & -11.15 & 5 & .387 & .312 & -5.87 & 2 & .433 & .367 & -9.45 \\
\hline 3 & .597 & .545 & -11.90 & 9 & .474 & .418 & -8.32 & 4 & .472 & .406 & -9.33 \\
\hline 6 & .629 & .578 & -13.52 & 12 & .483 & .412 & -8.49 & 7 & .485 & .418 & -9.27 \\
\hline 8 & .645 & .598 & -13.07 & 22 & .428 & .362 & -7.32 & 10 & .490 & .423 & -9.78 \\
\hline 11 & .634 & .583 & -12.54 & 24 & .383 & .308 & -7.09 & 13 & .500 & .436 & -10.69 \\
\hline 14 & .601 & .547 & -12.06 & & & & & 15 & .608 & .553 & -13.45 \\
\hline 16 & .704 & .658 & -17.39 & & & & & 17 & .442 & .371 & -8.37 \\
\hline 18 & .533 & .476 & -9.46 & & & & & 19 & .600 & .543 & -13.29 \\
\hline \multirow[t]{2}{*}{20} & .671 & .625 & -14.70 & & & & & 21 & .546 & .487 & -9.69 \\
\hline & & & & & & & & 23 & .352 & .286 & -6.82 \\
\hline
\end{tabular}

Tablo 4 incelendiğinde ölçekte yer alan maddelerin yeterince ayırt edici, yüksek geçerliğe sahip ve aynı yapıyı ölçen maddeler oldukları görülebilmektedir. Ölçeğin tümü ile alt faktörleri arasındaki ilişkiler de hesaplanarak aşağıda Tablo 5 'te sunulmuştur.

Tablo 5. Ölçek ve Alt Faktörleri Arasındaki Korelasyonlar

\begin{tabular}{lcccc}
\hline & Olumlu Tutumlar & Olumsuz Tutumlar & Teknoloji & GYTÖ \\
\hline Olumlu Tutumlar & 1 & $.606^{*}$ & $.122^{*}$ & $.788^{*}$ \\
Olumsuz Tutumlar & & 1 & $.016^{*}$ & $.619^{*}$ \\
Teknoloji & & & 1 & $.667^{*}$ \\
GYTÖ & & & & 1 \\
\hline$p^{*}<.01$ & & & &
\end{tabular}

Tablo 5 incelendiğinde alt faktörlerinin ölçeğin tümüyle orta ve yüksek derecede ilişkili olduğu görülmektedir.

Üçüncü Araştırma Problemi: Ölçeğin doğrulayıcı faktör analizi (DFA) bulguları nelerdir?

AFA sonrası elde edilen 24 maddelik yapının doğrulanması amacıyla yapılan DFA sonucunda, aşağıdaki bulgular elde edilmiştir.

Tablo 6. GYTÖ’nün DFA Bulguları

\begin{tabular}{lccccccc}
\hline Indeksler & $\mathrm{X}^{2} / \mathrm{sd}$ & $\mathrm{RMSEA}$ & $\mathrm{NFI}$ & $\mathrm{NNFI}$ & $\mathrm{CFI}$ & $\mathrm{RMR}$ & SRMR \\
\hline Değer & 2.21 & .06 & .95 & .97 & .97 & .09 & .06 \\
\hline
\end{tabular}

Tablo 6 incelendiğinde X²/sd değerinin 2.21 olarak elde edildiği görülmektedir. RMSEA değeri .06, NFI ve NNFI değerleri sırsıyla .95 ve .97 olarak hesaplanmıştr. CFI değeri .97 olarak elde edilirken, RMR ve SRMR değerleri sırasıyla .09 ve .06 olarak belirlenmiştir. DFA sonucu elde edilen grafik ise aşağıda Şekil 2'de sunulmuştur. 


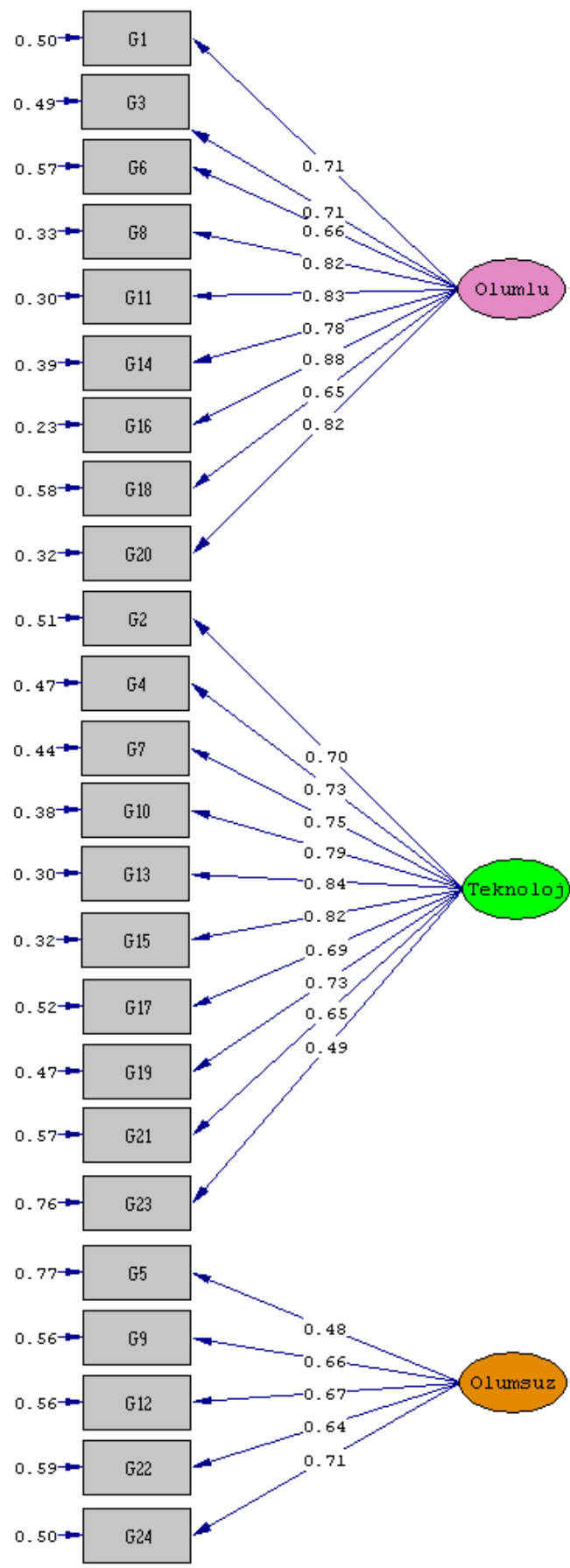

\section{Şekil 2. GYTÖ’nün DFA Grafiği}

Dördüncü Araştırma Problemi: Ölçeğin güvenirlik analizi bulguları nelerdir?

Güvenirlik analizleri için ilk olarak ölçeğin 30 maddelik haline ilişkin Cronbach alfa güvenirliği hesaplanmış ve 916 olarak elde edilmiştir. AFA sonrası çıkarılan altı maddeden sonra kalan 24 madde ile ilgili güvenirlik analizleri yapılmıştır. Elde edilen bulgular aşağıda Tablo 7'de verilmiştir.

\section{Tablo 7. GYTÖ’nün Güvenirlik Analizi Sonuçları}

\begin{tabular}{lcccc}
\hline Faktörler & Olumlu Tutumlar & Olumsuz Tutumlar & Teknoloji & GYTÖ \\
\hline Cronbach alfa & .924 & .728 & .909 & .886 \\
\hline
\end{tabular}

Tablo 7'ye göre ölçeğin tümüne ait Cronbach alfa iç tutarlığı .886 olarak görülmektedir. Olumlu tutumlar faktörünün iç tutarlılığı .924, olumsuz tutumlar faktörünün iç tutarlılı̆ı . .728 ve teknoloji faktörünün iç tutarlıı̆̆ı ise .909 olarak elde edilmiştir. 


\section{Sonuçlar}

Ortaokul öğrencilerinin geometriye yönelik tutumlarına ilişkin ölçek geliştirme çalışmasında ilk olarak madde havuzu oluşturulmuştur. Maddeler uzman görüşlerinin alınabilmesi için, uzman görüş formuna göre düzenlenmiş ve uzman görüşleri alınmıştır. Bu sürecin ardından ölçek uygulamaya hazır hale getirilmiştir. Uygulamanın gerçekleştirilmesinin ardından veriler titizlikle incelenmiş, daha sonra analizlerin yapılabilmesi için bilgisayar ortamına aktarılmıştır. Analize hazır hale getirilen veriler ile ölçeğin faktör yapısının belirlenmesi amacıyla AFA uygulaması gerçekleştirilmiştir. Sonuçta 24 madde ve üç faktörlü bir yapı elde edilmiştir. Bu faktörler; olumlu tutumlar, olumsuz tutumlar ve teknoloji olarak isimlendirilmişlerdir. Olumlu tutumlar ile ilgili maddeler; $1,3,6,8,11,14,16,18$ ve $20^{\prime}$ dir. Olumsuz tutumlar ile ilgili maddeler; 5, 9, 12, 22 ve 24'tür. Teknoloji faktörü ile ilgili maddeler ise; 2, 4, 7, 10, 13, 15, 17, 19, 21 ve 23'tür. Olumsuz tutumlar faktörü altındaki tüm maddeler ters maddelerdir. Olumlu tutumlar faktörünün açıkladığı varyans oranı \%23.782 olarak elde edilirken bu faktörde toplanan maddelerin yüklerinin .642 ve .826 arasında değiştiği ortaya çıkmıştır. Olumsuz tutumlar faktörünün açıkladığı varyans oranı $\% 10.580$ olarak hesaplanırken bu faktörde toplanan maddelerin yüklerinin ise .530 ile .741 arasında değiştiği tespit edilmiştir. Teknoloji faktörünün açıkladığı varyans oranı ise \%23.091 olup bu faktörde yer alan madde yüklerinin .534 ile .815 arasında değiştiği belirlenmiştir. Ölçeğin açıkladığı toplam varyans oranı ise \%57.453 olarak hesaplanmıştı. Çok faktörlü ölçek geliştirme çalışmalarında açıklanan varyans oranının \%40 ile \%60 arasında olması yeterli görülmektedir (Çokluk, Şekercioğlu, \& Büyüköztürk, 2010). Bu bağlamda elde edilen varyans oranı yeterli olarak değerlendirilmiştir.

Daha sonra madde analiz işlemleri gerçekleştirilerek ölçekte yer alan maddelerin yeterince ayırt edici, geçerli ve aynı yapıyı ölçer nitelikte oldukları ortaya konmuştur. Ölçek alt faktörleri arasındaki korelasyonlar ile alt faktörlerin ölçeğin tümü ile olan ilişki incelenmiştir. Büyüköztürk (2012) elde edilen korelasyon katsayısının .30-.70 arasında olmasını orta; .70-1.00 arasında olmasını yüksek ilişki olarak ifade etmektedir. Olumlu tutumlar alt faktörü ile ölçeğin tümü için elde edilen korelasyon değer .788 olarak elde edilmiş ve arada yüksek derecede bir ilişki olduğu ortaya konmuştur. Olumsuz tutumlar ve teknoloji alt faktörleri için elde edilen korelasyon katsayıları ise sırasıyla .619 ve .677 olarak hesaplanmıştr. Bu bağlamda bu faktörlerin de ölçekle orta düzeyde ilişkili olduğu sonucu elde edilmiştir.

Doğrulayıcı faktör analizinde $X^{2} /$ sd oranının 2.5 ve daha düşük olması mükemmel uyumu $(K l i n e, 2005)$ ifade etmektedir. Bu çalışmadaki bu oran 2.21 olup mükemmel uyum ortaya konmuştur. RMSEA değerinin ise .06 ve daha düşük olması iyi uyumu göstermektedir (Thompson, 2004). Bu çalışmada da benzer bir sonuç elde edilmiş ve ölçeğin iyi uyum sergilediği belirlenmiştir. NFI ve NNFI değerlerinin .95 ve daha yüksek olması mükemmel uyumu işaret etmektedir (Sümer, 2000). Bu çalışmada NFI değeri .95 ve NNFI değeri .97 elde edilmiş ve ölçeğin mükemmel uyum gösterdiği görülmüştür. CFI değerinin de .95 ve daha yüksek olması mükemmel uyumu göstermektedir (Thompson, 2004). Bu çalışmada elde edilen CFI değeri .97 olup mükemmel uyumu ortaya koymuştur. RMR ve SRMR değerlerinin ise .08 'den küçük olması iyi uyumu, .10’a eşit veya küçük olması ise vasat uyumu belirtmektedir (Brown, 2006; Kline, 2005). Çalışmadaki RMR ve SRMR değerleri ise sırasıyla iyi ve vasat uyumu göstermişlerdir.

Son olarak ölçeğin güvenirlik analizleri gerçekleştirilmiştir. Ölçeğin tümüne ait Cronbach alfa iç tutarlılık katsayısı .886 olarak elde edilmiştir. Ölçeğin olumlu, olumsuz ve teknoloji alt faktörlerine ilişkin güvenirlik katsayıları ise sırasıyla $.924, .728$ ve .909 olarak hesaplanmıştır. Hesaplanan güvenirlik katsayılarının .70 ve üzerinde olması genel olarak yeterli görüldüğünden (Büyüköztürk, 2012) elde edilen iç tutarlılık katsayıları yeterli olarak değerlendirilmiştir.

Sonuçta ortaokul düzeyinde öğrenim görmekte olan öğrencilerin geometriye yönelik tutumlarını ölçebilecek geçerli ve güvenilir bir ölçek ortaya konmuştur. Ölçeğin lise veya ilkokul düzeyinde kullanılıp kullanılamayacağı sınanmalıdır. Bu sebeple bu seviyede öğrenim gören öğrencilerin çalışma grubu olarak belirlendiği yeni çalışmaların yapılması önerilmektedir.

\section{Kaynakça}

Abdullah, A. H., \& Zakaria, E. (2011). An exploratory factor analysis of an attitude towards geometry survey in a Malaysian context. International Journal of Academic Reserach, 3(6), 190-193.

Aiken L. R (1979). Attitudes toward mathematics and science in Iranian middle schools. School Science and Mathematics, 79, $229-234$.

Atasoy, B. (2004). Fen öğrenimi ve öğretimi. Ankara: Asıl Yayın Dağıtım.

Avcı, E., Coşkuntuncel, O., \& İnandı, Y. (2011). Ortaöğretim on ikinci sınıf öğrencilerinin matematik dersine karşı tutumları. Mersin Üniversitesi Eğitim Fakültesi Dergisi, 7(1), 50-58.

Baki, A. (2008). Kuramdan uygulamaya matematik eğitimi (Genişletilmiş 4. Baskı). Trabzon: Harf Eğitim Yayıncılık.

Bal, A. P. (2014). Predictor variables for primary school students related to Van Hiele geometric thinking. Journal of Theory and Practice in Education, 10(1), 259-278.

Bayram, S. (2004). The effect of instruction with concrete models on eighth grade students' geometry achievement and attitudes toward geometry. Unpublished master thesis, Middle East Technical University Secondary Science and Mathematics Education, Ankara.

| Kastamonu Eğitim Dergisi, 27(4), 2019| 
Bindak, R. (2004). Geometri tutum ölçeği güvenirlik geçerlik çalışması ve bir uygulama. Doktora tezi, Dicle Üniversitesi Fen Bilimleri Enstitüsü, Diyarbakır.

Brown, T. A. (2006). Confirmatory factor analysis for applied research. NY: Guilford Publications, Inc.

Bulut, S., Ekici, C., İşeri, A. İ., \& Helvacı, E. (2002). Geometriye yönelik bir tutum ölçeği. Eğitim ve Bilim, 125, 3-7.

Büyüköztürk, Ş. (2012). Sosyal bilimler için veri analizi el kitabı. Ankara: Pegem Akademi.

Büyüköztürk, Ş., Kılıç-Çakmak, E., Akgün, Ö. E., Karadeniz, Ş., \& Demirel, F. (2012). Bilimsel araştırma yöntemleri. Ankara: Pegem Akademi. Büyüköztürk, Ş., Çakan, M., Tan, Ş., \& Atar, H. Y. (2014a). TIMSS 2011 ulusal matematik ve fen raporu-4. sınıflar. Ankara: İşkur Matbaacılık. Büyüköztürk, Ş., Çakan, M., Tan, Ş., \& Atar, H. Y. (2014b). TIMSS 2011 ulusal matematik ve fen raporu-8. sınıflar. Ankara: İşkur Matbaacılık. Cansız-Aktaş, M., \& Aktaş, D. Y. (2013). Geometriye yönelik güncel bir tutum ölçeğinin geliştirilmesi. Necatibey Eğitim Fakültesi Elektronik Fen ve Matematik Eğitimi Dergisi, 7(2), 225-247.

Comrey, A., \& Lee, H. (1992). A first course in factor analysis. Hillsdale, NJ: Erlbaum.

Çokluk, Ö., Şekercioğlu, G., \& Büyüköztürk, Ş. (2010). Sosyal bilimler için çok değişkenli istatistik SPSS ve LISREL uygulamaları. Ankara: Pegem Akademi.

Duatepe-Paksu, A., \& Ubuz, B. (2007). The development of a geometry attitude scale. Academic Exchange Quarterly, $11(2), 205$.

Fennema, E., \& Sherman, J. A. (1976). Fennema-Sherman mathematics attitudes scale: Instruments designed to measure attitudes toward the learning of mathematics by females and males. Journal for Reserach in Mathematics Education, 7(5), 324-326.

Gürefe, N., \& Kan, A. (2013). The study of validity and reliability of the attitude scale on the subject of geometric objects for the prospective teachers. Elementary Education Online, 2(12), 356-366.

Güven, Y. (2006). Farklı geometrik çizim yöntemleri kullanımının öğrencilerin başarı, tutum ve Van Hiele geometri anlama düzeylerine etkisi. Yayınlanmamış yüksek lisans tezi, Karadeniz Teknik Üniversitesi Fen Bilimleri Enstitüsü, Trabzon.

Kaba, Y., Boğazlıyan, D., \& Daymaz, B. (2016). Ortaokul öğrencilerinin geometriye yönelik tutumları ve öz-yeterlikleri. The Journal of Academic Social Science Studies, 52(Winter-I), 335-350. doi: 10.9761/JASSS3727

Kalaycı, Ş. (2005). Faktör analizi. İçinde Ş. Kalaycı (Ed.), SPSS uygulamalı çok değişkenli istatistik teknikleri (ss. 321-331). Ankara: Asil Yayın Dağıtım Ltd. Şti.

Kline, P. (1994). An easy guide to factor analysis. New York: Routledge.

Kline, R. B. (2005). Principles and practice of structural equation modeling. NY: Guilford Publications, Inc.

MEB (Milli Eğitim Bakanlı̆ı) (2017). Matematik dersi öğretim programı (ilkokul ve ortaokul 1, 2, 3, 4, 5, 6, 7, ve 8. sınıflar). Ankara: Talim ve Terbiye Kurulu Başkanlığı.

Mogari, D. (2004). Attitudinal scale measures in Euclidean geometry: What do they measure? South African Journal of Education, 24(1), 1-4.

Napitupulu, B. (2001). An exploration of students' understanding and Van Hieles of thinking on geometric constructions. Unpublished master dissertation, Simon Fraser University, Canada.

Ravid, R. (1994). Practical statistics for educators. New York: University Press in America.

Sümer, N. (2000). Yapısal eşitlik modelleri. Türk Psikoloji Yazıları, 3(6), 49-74.

Şencan, H. (2005). Sosyal ve davranışsal ölçümlerde güvenilirlik ve geçerlik. Ankara: Seçkin Yayınları.

Tabachnick, B. G., \& Fidell, L. S. (2001). Using multivariate statistics. Boston: Allyn \& Bacon.

Thompson, B. (2004). Exploratory and confirmatory factor analysis: Understanding concepts and applications. Washington: American Psychological Association.

Utley, J. (2007). Construction and validity of geometry attitude scales. School Science and Mathematics, 107(3), 89-93.

Ünlü, M., \& Ertekin, E. (2018). Ortaokul öğrencileri için geometriye yönelik inanç ölçeği geliştirme çalışması. Kastamonu Eğitim Dergisi, 26(1), 39-48. doi:10.24106/kefdergi.346334

Van de Walle, J. A. (2001). Elementary and middle school mathematics: Teaching developmentally. Boston: Allyn and Bacon.

Yenilmez, K., \& Uygan, C. (2010). Yaratıcı drama yönteminin ilköğretim 7. sınıf öğrencilerinin geometriye yönelik öz-yeterlik inançlarına etkisi. Kastamonu Eğitim Dergisi, 3(18), 931-942.

Sunzuma, G., Masocha, M., \& Zezekwa, N. (2013). Secondary school students' attitudes towards their learning of geometry: A survey of bindura urban secondary schools. Greener Journal of Educational Research, 3(8), 402-410.

Struchens, M. E., Harris, K. A., \& Martin, W. G. (2001). Assesing geometric and measurement understanding using manipualtives. Mathematics Teaching in Middle School, 6(7), 402-405.

Tavşancıl, E. (2002). Tutumların ölçülmesi ve SPSS ile veri analizi. Ankara: Nobel Yayınları.

Taşdemir, C. (2008). illköğretim 6, 7 ve 8. sınıf öğrencilerinin matematik dersine yönelik tutumlarının bazı değişkenlere göre belirlenmesi: Bitlis ili örneği. KKEFD, 17, 185-201.

TDK (2018). Geometri. Retrieved from http://www.tdk.gov.tr/index.php?option=com_gts\&arama=gts\&guid=TDK.GTS.5b1451e77ca4e9.37566042 on 03.06.2018

Tutak, T. (2008). Somut nesneler ve dinamik geometri yazılımı kullanımın öğrencilerin bilişsel öğrenmelerine, tutumlarına ve Van Hiele geometri anlama düzeylerine etkisi. Doktora tezi, Karadeniz Teknik Üniversitesi Fen Bilimleri Enstitüsü, Trabzon

| Kastamonu Eğitim Dergisi, 27(4), 2019| 


\section{K 1: Geometriye Yönelik Tutum Ölçeği (GYTÖ)}

\begin{tabular}{|c|c|c|c|c|c|c|}
\hline & & 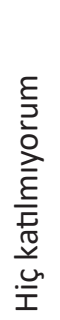 & 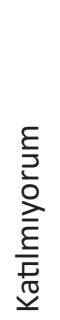 & 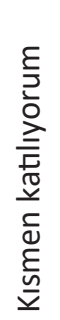 & 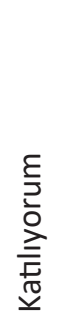 & 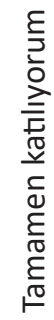 \\
\hline 1 & Geometri konularını diğer matematik konularına göre daha çok severek çalışırım. & & & & & \\
\hline 2 & $\begin{array}{l}\text { Geometri konuları işlenirken teknoloji (tablet, bilgisayar, akıllı tahta, vb. gibi) kullanılması hoşu- } \\
\text { ma gidiyor. }\end{array}$ & & & & & \\
\hline 3 & Matematikte en çok geometri konularını seviyorum. & & & & & \\
\hline 4 & Geometri konularının işlendiği derslerde öğretmeni teknolojiyi kullanmasını isterim. & & & & & \\
\hline 5 & Geometri konularını sevmiyorum. & & & & & \\
\hline 6 & Matematik konuları içerisinde daha fazla geometri konusu olmasını isterim. & & & & & \\
\hline 7 & Geometri konularında teknolojiyi kullanmak derse daha iyi odaklanmamı sağlıyor. & & & & & \\
\hline 8 & Matematikte geometri konularına sıra gelince kendimi mutlu hissederim. & & & & & \\
\hline 9 & Geometriden korkarım. & & & & & \\
\hline 10 & Geometri konularının işlendiği derslerde teknoloji kullanıldığı zaman dersi daha iyi anlıyorum. & & & & & \\
\hline 11 & Geometri problemlerini çözerken eğlenirim. & & & & & \\
\hline 12 & Geometri konularının işlendiği derslerde zaman geçmek bilmez. & & & & & \\
\hline 13 & Geometri derslerinde teknoloji kullanılmasını seviyorum. & & & & & \\
\hline 14 & Geometri problemleri bulmaca gibidir, çözerken zevk alırım. & & & & & \\
\hline 15 & Geometri konuları teknoloji kullanılarak işlendiğinde dersler daha zevkli geçiyor. & & & & & \\
\hline 16 & Geometri konuları eğlencelidir. & & & & & \\
\hline 17 & Geometri derslerinde teknolojiyi kullanmak önemlidir. & & & & & \\
\hline 18 & Geometri problemleri bana çok kolay gelir. & & & & & \\
\hline 19 & Teknoloji ile işlenen geometri dersleri, bana fayda sağlıyor. & & & & & \\
\hline 20 & Geometri problemlerini çözerken mutlu oluyorum. & & & & & \\
\hline 21 & Teknoloji desteği ile işlenen geometri dersleri dikkatimi çekip ilgimi artırıyor. & & & & & \\
\hline 22 & Geometri problemlerini diğer matematik problemlerine göre daha zor çözerim. & & & & & \\
\hline 23 & Derslerde geometriyi daha kolay anlamamızı sağlayacak programların kullanılmasını isterim. & & & & & \\
\hline 24 & Geometri problemlerini çözdükten sonra kendimi çok yorgun hissederim. & & & & & \\
\hline
\end{tabular}

